\title{
The Research of Small Molecule Soybean Polypeptide Precipitated by TCA
}

\author{
Jian XIONG ${ }^{1}$, Yu-Ke XIANG ${ }^{1}$, Jun $\mathrm{YE}^{2, \mathrm{a}, *}$, Yu-Hao $\mathrm{ZHANG}^{3, b}$ \\ ${ }^{1}$ School of Light Chemistry and Food Science, South China University of Technology, \\ Guangzhou 510640, China. \\ ${ }^{2}$ State Key Laboratory of Pulp and Paper Engineering, South China University of \\ Technology, Guangzhou 510640, China. \\ ${ }^{3}$ School of Food Science and Engineering, Southwest University, Chongqing 400715, \\ China \\ aemail: jye@scut.edu.cn, bemail: 49690507@qq.com \\ ${ }^{*}$ Corresponding authors
}

Keywords: Component, Soybean protein isolated, Trichloroacetic acid, Enzymolysis, Range of Molecular distribution.

\begin{abstract}
Trichloroacetic acid (tca) makes macromolecular peptides expose more hydrophobic groups and have precipitation effect. It's widely used in the desalination and concentration of protein and peptide. This experiment use the alkaline protease enzymolysis the soybean protein isolated and makes the products as raw material, then do the high performance liquid chromatography (hplc) analysis of tca precipitation before and after enzymolysis liquid. Macromolecular peptidesore more than 10000 completely precipitated. Results show that the precipitation rate of more than $3000 \mathrm{u}$ reached $62.01 \%$, the molecular weight of $3000-1000 \mathrm{u}$ is about $37.71 \%$. When the molecular weight is less than $1000 \mathrm{u}$, the polypeptide precipitation rate drops to $22.51 \%$. For the peak belonging $420 \mathrm{u}$, the main reason is that tca have strong absorption peak and a small amount of impurity absorption peak.
\end{abstract}

\section{Introduction}

Trichloroacetic acid (tca), because it can change the protein conformation into exposing more hydrophobic groups, can be regarded as a kind of protein and polypeptide precipitant used in all aspects of the related studies [1]. As an accepted protein precipitator in practical application, the dosage of tca is obtained by the gradient method. The weight range of the precipitation in the specific molecular, sedimentation rate didn't have actual research. The public usually think tca precipitation of tens to hundreds of thousands of peptides macromolecular components are completely [2] - [3], but the case of small molecular peptides have no detailed document to prove. For example, we use the tca/acetone solution to do the protein sample concentration and desalination. Now it has been clearly proposed that tca destroys the structure of the macromolecular and it was not easy to be clear, so it is mainly used for the enrichment and desalination of small polypeptides. For small molecule polypeptides, the molecular weight range and settling rate is not accurate. In-depth understanding of tca molecular weight range of ATP eptide precipitation and precipitation rate are good for correctly tca use [4], as far as possible reduces the experimental error. This experiment is based on hydrolysates of soy protein isolated, the hplc analysis of the before and after tca precipitation sample liquid. Then we 
compare its molecular weight distribution, and conclude the tca precipitation scope of small molecular peptide molecular weight and its precipitation rate.

\section{Materials and Methods}

\section{Materials}

Soybean protein isolated (spi), Alcalasa enzyme, tca, casein, copper sulfate, potassium sodium tartrate, formaldehyde, phenolphthalein, potassium acid phthalate, $\mathrm{NaOH}$ and $\mathrm{HCl}$, acetonitrile, trifluoroacetic acid and methanol.

Sample: cytochrome C $(\mathrm{Mw}=12500 \mathrm{Da})$, aprotinin $(\mathrm{Mw}=6511.44 \mathrm{Da})$, Bacitracin $(\mathrm{Mw}=1422.69 \mathrm{Da})$, Gly Gly - Tyr - Arg $(\mathrm{Mw}=451.48 \mathrm{Da})$

High performance liquid chromatography (LC-20 a Japanese), ultraviolet spectrophotometer (UV - 2450, Japan), fully automatic kjeldahl nitrogen determination apparatus (KjelFlex K - 360).

\section{Methods}

The Preparation of Samples. [5, 6] SPI (2.5g) contains about $90 \%$ high-quality protein. Distilled water was added to form $5 \%$ solution and placed in a boiling water bath for $10 \mathrm{~min}$. Then it was cooled to $53^{\circ} \mathrm{C}$. $\mathrm{NaOH}$ solution was used to adjust the $\mathrm{pH}$ $(=8)$ value of the initial reaction. Alkaline protease $(3642 \mathrm{u} / \mathrm{g})$ was joined to react for $30 \mathrm{~min}, 1 \mathrm{~h}, 2 \mathrm{~h}$ and $4 \mathrm{~h}$. The reaction solution was adjusted $\mathrm{ph}=4.5$ by $\mathrm{HCl}$. After that, the solution was immersed in a boiling water bath for $15 \mathrm{~min}$ to inactivate the enzyme. The reaction solution was then centrifuged at $4000 \mathrm{r} / \mathrm{min}$ for $20 \mathrm{~min}$, and the supernatant was filtered to obtain the spi hydrolyzate.

The Determination of Total Protein Content. [7] GB 50095-2010, the content of protein was $88.57 \%$.

Degree of Hydrolysis. [8] Formaldehyde titration.

The Yield of Peptides. [9, 10] The preparation of standard curve (casein), Biuret method is to determine the rate of peptide.

Fractionation of SPI Hydrolysates by HPLC. The chromatographic conditions [11]:7.8 $\times 300 \mathrm{~mm}$ (Waters) with a C18 cartridge as guard column. Mobile phase: acetonitrile/water/trifluoroacetic acid and $0.1 / 45 / 55(\mathrm{~V} / \mathrm{V})$, the flow rate was 0.5 $\mathrm{mL} / \mathrm{min}$. Detection was carried out at $220 \mathrm{~nm}$. Standard sample: cytochrome $\mathrm{C}(\mathrm{Mw}=$ $12500 \mathrm{Da})$, aprotinin $(\mathrm{Mw}=6511.44 \mathrm{Da})$, Bacitracin $(\mathrm{Mw}=1422.69 \mathrm{Da})$, Gly Gly Tyr $-\operatorname{Arg}(\mathrm{Mw}=451.48 \mathrm{Da})$

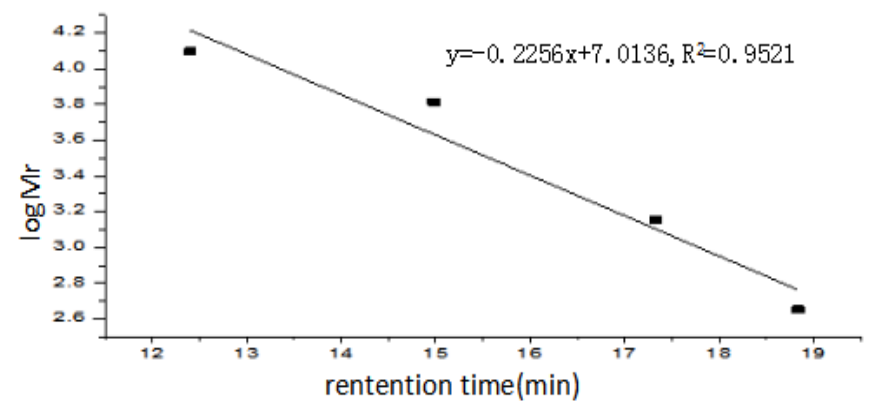

Figure.1 HPLC standard sample figure

Samples analysis: The sample solution $5 \mathrm{ml}$ combined with $5 \mathrm{ml} 20 \%$ of TCA shocked $10 \mathrm{~s}$ and stood for $10 \mathrm{~min}$, centrifuged $20 \mathrm{~min}$ under $8000 \mathrm{r} / \mathrm{min}$, separated out clear liquid. In addition, we let the same enzymolysis liquid mix with pure water $(1: 1)$, ditto. Finally, the same amount of samples was taken by a syringe, respectively passed 
the filtration membrane and analyzed. Under the condition of the chromatographic analysis, the chromatographic data of the sample was taken into the standard curve equation to calculate to get the peptide molecular weight and its distribution range [12].

\section{Results and Discussion}

\section{Different Time of Digestion}

The Impact on the Degree of Hydrolysis. From Fig. 2, at the beginning of the enzyme solution, the degree of hydrolysis increased sharply with the extension of time.1h later, hydrolysis degree tended to be stable. After $4 \mathrm{~h}, \mathrm{DH}$ value reached $16.37 \%$.

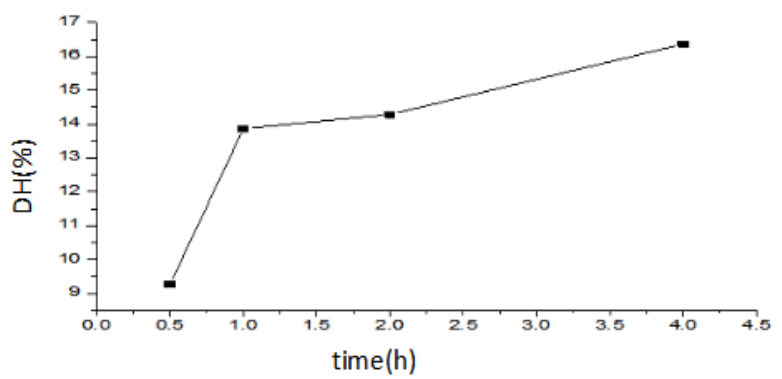

Figure 2. Variation of degree of hydrolysis with time

The Impact on the Peptide Yield. From Fig. 3, as time extended, because of a small amount of peptide reconnection, the degree of peptides drops. The last peptide yield is $77.30 \%$.

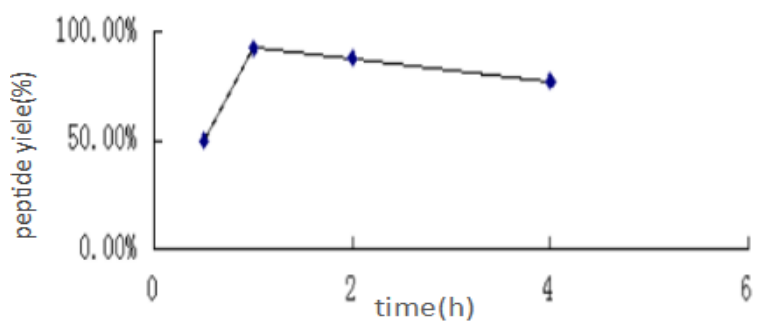

Figure 3. Enzymatic hydrolysis time and peptide yield

\section{The Analysis of HPLC}

From Fig. 4 , the molecular weight distribution of the sample without tca is $13800 \mathrm{u}$ $426 \mathrm{u}$.After the precipitation, a range become $2950 \mathrm{u}-426 \mathrm{u}$.There were two peaks at 23.5and 32.15 min. From the Fig. 5, we concluded that $10 \%$ TCA solution has two big peaks at 23.5 and 32.1 at $220 \mathrm{~nm}$.

(a)

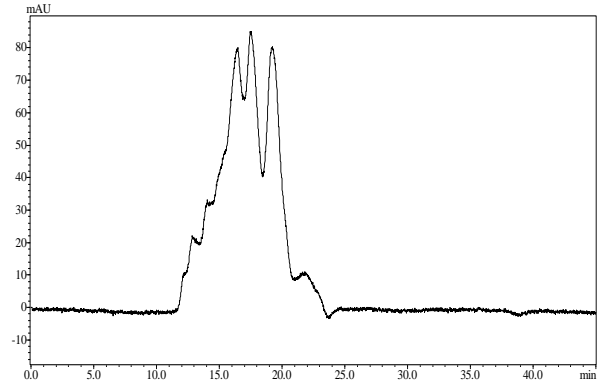

(b)

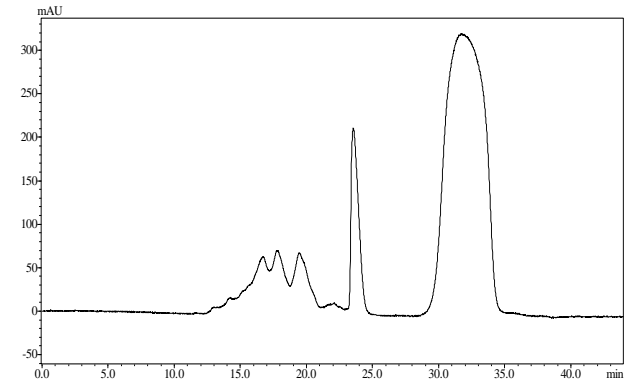

Figure 4. The HPLC spectrum of $0.5 \mathrm{~h}$ enzymic hydrolysis hydrolysis solustion without the precipitated of the tca (a) and with the precipitated of the tca (b) 


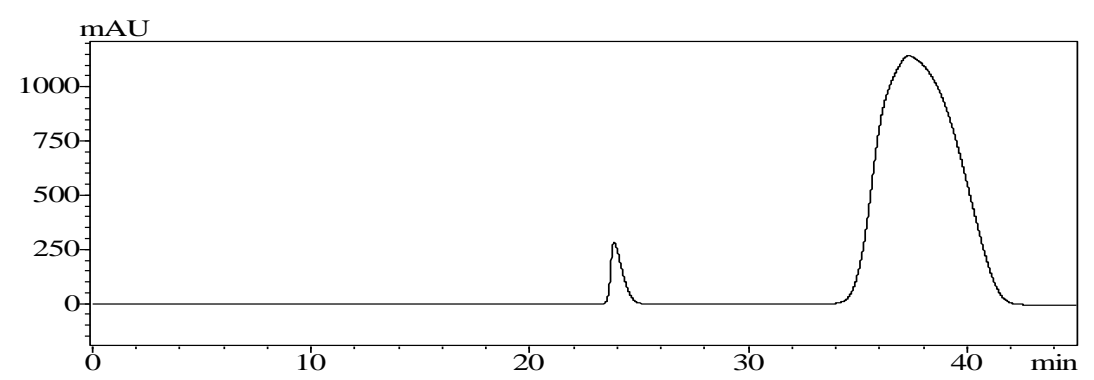

Figure 5. the chromatogram of $10 \%$ tca solution at $220 \mathrm{~nm}$

Integrating all the chromatogram get the comprehensive analysis (table 1).It is concluded that enzymolysis liquid of total peak area is increasing as time goes by. More than $3000 \mathrm{u}$ peptides area is $14.8154 \%, 7.4609 \%, 10.7445 \%, 8.7006 \%$ respectively in $0.5 \mathrm{~h}, 1 \mathrm{~h}, 2 \mathrm{~h}, 4 \mathrm{~h}$. The rate of this range is gradually decline. The $3000-1000 \mathrm{u}$ in the first three is relatively stable at about $41 \%$. The main reason is that both consumption and complement. At $4 \mathrm{~h}$, it fell down to $17.18 \%$. The peak time of $1000 \mathrm{u}$ probably appeared at $17.79 \mathrm{~min}$. The $1000 \mathrm{u}$ tended to be stable in the first 2 hours .Then it began to increase, up to $65.856 \%$ at 4 .

Table 1. Time-The molecular weight-Square-Precipitation rate

\begin{tabular}{|c|c|c|c|c|c|c|}
\hline$\underbrace{\mathrm{TI}}_{\mathrm{MWD}}$ & n) & $30 \mathrm{~min}$ & $1 \mathrm{~h}$ & $2 \mathrm{~h}$ & $4 h$ & $\begin{array}{c}\text { The } \\
\text { average } \\
\text { Precipita } \\
\text { tion rate }\end{array}$ \\
\hline \multirow{3}{*}{$>3000$} & The peak area & 6787157 & 5911631 & 5248697 & 4556613 & \multirow{3}{*}{0.6201} \\
\hline & $\begin{array}{l}\text { The peak } \\
\text { area(tca) }\end{array}$ & 2038903 & 2152282 & 2164943 & 2017469 & \\
\hline & Precipitation rate & 0.699594 & 0.635924 & 0.587528 & 0.557244 & \\
\hline \multirow{3}{*}{$3000-1000$} & The peak area & 1294268 & 12780259 & 12766295 & 5591664 & \multirow{3}{*}{0.3771} \\
\hline & $\begin{array}{l}\text { The peak } \\
\text { area(tca) }\end{array}$ & 1119716 & 5950119 & 5401304 & 4125829 & \\
\hline & Precipitation rate & 0.134865 & 0.534428 & 0.576909 & 0.262146 & \\
\hline \multirow{3}{*}{$<1000$} & The peak area & 7244812 & 7922166 & 8946568 & 19574430 & \multirow{3}{*}{0.2251} \\
\hline & $\begin{array}{l}\text { The peak } \\
\text { area(tca) }\end{array}$ & 5642828 & 6614318 & 6190746 & 15680459 & \\
\hline & Precipitation rate & 0.221122 & 0.165087 & 0.308031 & 0.206351 & \\
\hline \multirow{3}{*}{ Totle area } & The peak area & 15326241 & 26614056 & 26961560 & 29722707 & \multirow{3}{*}{0.4071} \\
\hline & $\begin{array}{l}\text { The peak } \\
\text { area(tca) }\end{array}$ & 8801447 & 14716719 & 13756993 & 21823757 & \\
\hline & Precipitation rate & 0.4257269 & 0.447032 & 0.489755 & 0.265754 & \\
\hline
\end{tabular}

Tca has different ability of precipitation with the different molecular weight .For more than $3000 \mathrm{u}$, precipitation rate reached $62.01 \%$. The $3000-1000 \mathrm{u}$ is about $37.71 \%$. when the molecular weight less than $1000 \mathrm{u}$, the rate comes to $22.51 \%$.At the 1,2 hours, because each component content is stable, tca precipitation rate is respectively $42.57 \%$, $44.70 \%, 48.98 \%$. Two hours later, forming large numbers of small molecular peptides, 
the rate is significantly reduced to $26.58 \%$. For the peak belonging $420 \mathrm{u}$, because of the addition of tca with some impurities, the precipitation area is bigger. The main reason is that tca have strong absorption peak and a small amount of impurity absorption peak. Thus concluded that tca has different precipitation rate between $9549609 \mathrm{u}$ to $420 \mathrm{u}$. In daily life, we thought there is no precipitation rate at $1000 \mathrm{u}$. In fact, less than $1000 \mathrm{u}$ still have slightly precipitation rate.

\section{Conclusion}

The digestibility of alkaline protease increased with time. At $4 \mathrm{~h}$, enzymolysis achieve stability. The degree of hydrolysis was $16.37 \%$, the peptide yield was $77.30 \%$. The total peak area was still increased. With the extension of reaction time, the proportion of macromolecular peptides decreased and the ratio of small one increased.

Tca played a certain precipitation role of proteins and peptides. For more than $3000 \mathrm{u}$, the precipitation rate reached $62.01 \% .3000-1000 \mathrm{u}$, the rate was about $37.71 \%$, less than $1000 \mathrm{u}$; the rate became $22.51 \%$, mainly concentrated in the $900 \mathrm{u}-1000 \mathrm{u}$. Tca had strong absorption peak in $220 \mathrm{~nm}$.

\section{Acknowledgement}

We gratefully acknowledge the financial support provided by the National Natural Foundation of China (project 31270617) and State Key Laboratory of Pulp and Paper Engineering (Project 2015D03).

\section{References}

[1] AJ Link, J LaBaer, Trichloroacetic acid (TCA) precipitation of Proteins, 2011(8): 993

[2] J Kroll, HM Rawe. Reactions of plant phenols with myoglobin: influence of chemical structure of the phenolic compounds, Food Science, 2001, 66:48-58

[3] L Koontz, TCA precipitation, Methods in enzymology, 2013, 541:3-10

[4] T S Templeman, D A Stetler, Plant Physiol., 1987, 85:343-349

[5] D Agrawal, P Patidar, Production of alkaline protease by Penicillium sp. under SSF conditions and its application tosoy protein hydrolysis, Process Biochemistry, 2004, 39: $977-981$

[6] HG Kristinsson, BA Rasco, Kinetics of the hydrolysis of Atlantic salmon (Salmo salar) muscle proteins by alkaline proteases and a visceral serine protease mixture, Process Biochemistry, 2000, 36:131-139

[7] GB 50095-2010

[8] PM Nielsen, D Petersen, Improved method for determining food protein degree of hydrolysis, Food Science, 2001,66, No. 5,

[9] AL Weber, LE Orgel, The formation of peptides from glycine thioesters, Molecular Evolution, 1979, 13:193-202

[10] G Picariello, G Mamone, Protein digestomics: Integrated platforms to study food-protein digestion and derived functional and active peptides, Trends in Analytical Chemistry 2013,52:120-134 
[11] B Hernández-Ledesma, Preparation of antioxidant enzymatic hydrolysates from $\alpha$-lactalbumin and $\beta$-lactoglobulin. Identification of active peptides by HPLC-MS/MS. Agricultural and food chemistry, 2005 .53, 588-593

[12] V Faoro, G Stanta, Trichloroacetic Acid (tca) Precipitation of Proteins, Guidelines for Molecular Analysis, 2011:257-258 